\title{
Hypnotizability-Related Cerebral Blood Flow
}

\author{
Anas Rashid ${ }^{1}$, Enrica Laura Santarcangelo ${ }^{2,}{ }^{*}$, Silvestro Roatta ${ }^{1}$ \\ 1 Lab of Integrative Physiology, Department of Neuroscience "Rita Levi Montalcini”, University of Torino, \\ Torino, Italy; anas.rashid@unito.it; silvestro.roatta@unito.it \\ 2 Lab of Cognitive and Behavioral Neuroscience, Department of Translational Research and New Technolo- \\ gies in Medicine and Surgery, University of Pisa, Pisa, Italy; enrica.santarcangelo@unipi.it \\ * Correspondence: enrica.santarcangelo@unipi.it; Tel.: +39 0502213465
}

\begin{abstract}
Hypnotizability is a cognitive trait associated with differences in the brachial artery flowmediated dilatation of individuals with high hypnotizability (highs) and low hypnotizability scores (lows). The study investigated possible hypnotizability-related cerebrovascular differences. Among 24 healthy volunteers the Stanford Hypnotic Susceptibility Scale Form A, identified 13 medium-tolows (med-lows), 11 medium-to-highs (med-highs), 1 medium hypnotizable. Hypnotizability did not influence the significant changes produced by the trail making task (TMT), mental arithmetic task (MAT), hyperventilation (HVT) and rebreathing (RBT) on Heart rate (HR), arterial blood pressure $(\mathrm{ABP})$ and partial pressure of end-tidal $\mathrm{CO}_{2}\left(\mathrm{PeTCO}_{2}\right)$ and oxygenation (TOI); but moderated the correlations between the changes occurring during tasks with respect to basal conditions $(\Delta)$ in $\mathrm{ABP}$ and $\mathrm{PeTCO}_{2}$ with MCAv. In HVT, med-lows exhibited a significant correlation between $\Delta \mathrm{M}$ $\mathrm{CAv}$ and $\triangle \mathrm{PETCO}_{2}$, med-highs showed a significant correlation between $\triangle \mathrm{ABP}$ and $\triangle \mathrm{MCAv}$; a significant correlation between $\Delta \mathrm{THI}$ and $\Delta \mathrm{TOI}$ was observed in medium lows. Cerebrovascular reactivity (CVR) and conductance $(\triangle \mathrm{CVCi})$ were significantly correlated with $\triangle \mathrm{MCAv}$ in med-lows during HVT and RBT. Findings represent the first assessment of hypnotizability-related differences in the mechanisms controlling the middle cerebral artery flow velocity, cerebrovascular reactivity and conductance in response to hyperventilation and rebreathing.
\end{abstract}

Keywords: Doppler, NIRS, hyperventilation, rebreathing, cognitive tasks, hypnotic susceptibility

\section{Introduction}

Hypnotizability - the proneness to modify perception, memory, and behavior according to specific suggestions and to enter the hypnotic state [1] - is a psychophysiological trait [2] measured by scales whose score is stable during adulthood [3]. The individuals with high (highs) and low hypnotizability scores (lows) display different morphofunctional brain characteristics mainly concerning the salience and executive networks [4] and the cerebellum [5]. They also exhibit differences in the cognitive, sensorimotor, and cardiovascular domains observable in the absence of hypnotic induction and suggestions, thus being relevant to everyday life [2]. For instance, with respect to lows and medium hypnotizable individuals (mediums), highs show the greater ability of attention and dissociation [6-8], stronger functional equivalence between imagery and perception $[9,10]$, low interoceptive accuracy [11] and greater interoceptive sensitivity [12], less close postural and visuomotor control [2].

In the vascular system, the brachial artery post occlusion flow-mediated dilatation (FMD) is similar in highs and lows in basal conditions, whereas FMD is less impaired in highs than in lows during nociceptive stimulation [13] and not impaired at all in highs during mental stress, at variance with lows and the general population [14,15]. This can be accounted by different control of the release of nitric oxide (NO) by endothelial cells [16] in highs and lows/general population during cognitive and physical stimulation.

The hypnotizability-related differences in the cerebral arteries blood flow possibly due to different NO availability have not been studied. They could be relevant to the 
observed negative correlation between hypnotizability and brain total grey matter volume $[4,5,8]$. The NO is required, in fact, for the development and maturation of the nervous tissue, but its excessive amount can be toxic, mainly for regions particularly rich in NO such as cerebellum and hippocampus [17].

\subsection{Changes in the cerebral arteries diameter induced by hypercapnia/hypocapnia and arterial pressure}

In the brain tissue, perfusion, or cerebral blood flow $(\mathrm{CBF})$, is a measure of the rate of delivery of arterial blood to a capillary bed [18]. Hypocapnia is associated with reduced CBF [19], NO availability [20] and arteries diameter [21] not depending on extracellular $\mathrm{pH}$ [22]. It seems unlikely that the formation of $\mathrm{NO}$ is the only mechanism involved in hypercapnia, because increases in CBF during very high levels of hypercapnia $(>100$ $\mathrm{mmHg}$ ) are not altered by the inhibition of $\mathrm{NO}$ synthase. In contrast, vasodilation during moderate hypercapnia appears to be dependent on the production of NO due to increased activity of NO synthase [23]. Another possibility is that NO is not the direct mediator of vessels relaxation but that normal basal levels of $\mathrm{NO}$ and/or cGMP are required for the response to hypercapnia to occur [24].

The hypothesis that the artery dilation may be mediated by a decreased $\mathrm{pH}$ in the extracellular fluid, as $\mathrm{CO}_{2}$ freely diffuses across the cerebrovascular endothelium, is contradicted by experiments reporting the effects of blockade of the cerebrovascular action of $\mathrm{CO}_{2}$ by brainstem lesions [25,26] or decerebration [27-29], cholinergic blockers [30-33], inhibitors of prostaglandin [34,35] and NO synthesis [36].

The cerebrovascular changes induced by increased or decreased $\mathrm{CO}_{2}$ cannot be reliably studied without concomitant assessment of arterial blood pressure [37]. It has also been shown, however, that NO release is not obligatory for cerebrovascular reactivity to $\mathrm{CO}_{2}$, whereas transient increases in $\mathrm{CBF}$ induced by increases in blood pressure mostly rely on NO release [38]. Cerebral autoregulation, in fact, stabilizes blood flow by buffering steady state increase in cerebral perfusion pressure, but cannot compensate for brief elevations in blood pressure and consequent increases in CBF $[39,40]$.

\subsection{Changes in the cerebral arteries diameter induced by brain activity}

NO mediates the brain vessels dilation which follows increased neuronal activity leading to the increased need for $\mathrm{O}_{2}$ supply [41,42]. In this perspective, we may expect that hypnotizability-related differences in the cerebral artery diameters occur during cognitive tasks. The highs' greater proneness to focused attention and absorption [6,43], in fact, might enable them to activate task-related areas more than lows' and, thus, exhibit larger increase in CBF. On the other hand, the highs' greater attentional abilities [43-45] may require less neural engagement, as observed, for instance, in motor imagery tasks performed by individuals with greater motor experience of those tasks [46]. In addition, the highs' and lows' modes of information processing - that is, their neural activities - is different. During sensory and cognitive tasks, the former display slight and diffuse changes in the general asset of brain activation, whereas the latter exhibit more localized task-related changes $[9,47,48]$. This may lead to negligible differences in the highs' brain metabolic changes during tasks with respect to basal conditions. Thus, we cannot reliably predict whether and how hypnotizability modulates cerebral hyperemia induced by cognitive tasks.

\subsection{Aim of the study}

The study was aimed to assess a) whether the flow velocity in the middle cerebral artery (MCAv) is influenced by hypnotizability during cognitive tasks, hyperventilation, and rebreathing; and $\mathrm{b}$ ) how MCAv is associated with partial pressure of end-tidal $\mathrm{CO}_{2}$, tissue oxygenation index and arterial blood pressure in participants with different hypnotizability. 


\section{Materials and Methods}

\subsection{Subjects}

Twenty-four healthy subjects (12 females; age: $26.1 \pm 4.5$ years), 20 right-handed and 4 left-handed according to the Edinburgh Handedness Inventory [49], were enrolled in this study. They were all University of Torino students with no medical, neurological and psychiatric disease, hypertension (resting blood pressure $<120 / 80 \mathrm{mmHg}$ ), sleep and attention disturbance, substance abuse throughout their life, drugs intake in the last 3 months.

\subsection{Experimental procedure}

The hypnotic assessment was performed by the validated Italian version of the Stanford Hypnotic Susceptibility Scale (SHSS), form A [50]; which is a behavioral scale classifying highs (score: 8-12 items passed out of 12), mediums (score: 5-7 out of 12) and lows (score: $0-4$ out of 12). It includes motor and cognitive items indicating motor inhibition, hallucination and dissociation abilities and its administration requires approximately 20 minutes. It was administered to all participants by the same expert experimenter. Owing to the small number of participants, they were divided in two groups: medium-lows (SHSS score: 0-5) and medium-highs (SHSS score: 7-12) hypnotizable.

Experiments had been conducted in a quiet, sound and light attenuated, temperature controlled $\left(21-23^{\circ} \mathrm{C}\right)$ room between 9 to $11 \mathrm{AM}$ and 4 to $6 \mathrm{PM}$; at least 3 hours after the latest food and caffeine/alcohol intake. Before starting the recordings, the partial pressure of end-tidal $\mathrm{CO}_{2}\left(\mathrm{PeTCO}_{2}\right)$ was measured and the signals visual feedback was provided to the participants invited to relax sitting in an armchair. After all signals reached a stable condition i.e., at least for 5 minutes, they were recorded for a 10 mins baseline period and during a sequence of four tasks separated from each other by a minimum of a 5 mins rest (with additional time if required by the participant) and randomly presented within medlows and med-highs.

Since hypnotizability is a stable individual trait [3] recordings performed 2 months earlier than hypnotic assessment could be reliably studied as a function of hypnotizability.

\subsection{Tests}

Before starting the tests sequence, participant received instructions and training to ensure that they were able to perform the tasks and respiratory maneuvers correctly. Each test consisted of a basal and a task condition. The test was pseudo randomly assigned within participants.

\subsubsection{Trail Making Task (TMT)}

The participant was instructed to connect the numbers (1 to 40) and 21 Italian letters (A to $\mathrm{Z}$ ) bylines in ascending sequence and performed on the paper over 3 minutes with alternating numbers and letters $(1-\mathrm{A}-2-\mathrm{B}-3-\mathrm{C}$ and so on).

\subsubsection{Mental Arithmetic Task (MAT)}

The participant was asked to progressively subtract the odd numbers $(1,3,5$, and so) from 1000 for 3 minutes, writing each result on a paper. One operator standing behind the subject monitored the outcome, promptly asking the subject to repeat the calculation in case of error.

After TMT and MAT, the participant was invited to rate the experienced cognitive fatigue using a numerical rating scale from 0 ( $\mathrm{min})$ to 10 ( $\max )$.

\subsubsection{Hyperventilation (HVT)}

The participant was asked to hyperventilate to achieve and maintain for 90 seconds the $50 \%$ of the normal $\mathrm{PETCO}_{2}$. To this end, they were provided with visual feedback from the display of the capnograph, which was continuously monitoring $\mathrm{P}_{\mathrm{ETCO}} \mathrm{C}_{2}$ from the 
expiratory flow collected by a nasal cannula and a horizontal cursor placed at $50 \% \mathrm{PeTCO}_{2}$ indicating the target $\mathrm{P}_{\mathrm{ETCO}}$.

\subsubsection{Rebreathing (RBT)}

The nose is closed with the help of a nose clip. The participant was asked to take a large breath of room air and then exhale into a previously empty plastic bag, closing the bag so that it stays full. Once the bag is full of expired air, the participant resumed the normal breathing in and out of the closed bag hence maintaining a spontaneous breathing frequency and when the participant begins to rebreathe, start the stopwatch. The participant should continue to rebreathe for 90 seconds. The cartoon was also connected with a sampling line to the capnograph to allow continuous recording of $\mathrm{PeтCO}_{2}$.

\subsection{Measurements}

The heart rate (HR, bpm) and arterial blood pressure (ABP, mmHg) were measured by continuous finger-pulse photoplethysmography (CNAP Monitor 500, CNSystems Medizintechnik GmbH, Graz, Austria). Calibration of ABP was periodically performed using a regular pneumatic cuff at the right arm.

A capnograph (Capnostream $^{\mathrm{TM}}$ 20p Bedside Patient Monitor with Microstream ${ }^{\mathrm{TM}}$ Technology, Oridion, Ohmeda, USA) was used to monitor the partial pressure of endtidal carbon dioxide $\left(\mathrm{PETCO}_{2}\right)$ in the respiratory gases.

A continuous-wave near-infrared spectroscopy (NIRS) device (NIRO-200NX, Hamamatsu Photonics, Hamamatsu, Japan) was used to measure changes in tissue hemoglobin index (THI, a.u.), which represents the total hemoglobin concentration, and tissue oxygenation index (TOI, \%), which represents the percentage ratio of oxygenated to total hemoglobin. TOI was normalized to its basal value to minimize the effect of fluctuation. The device implements both the classical modified Beer-Lambert method [51] and the spatially-resolved spectroscopy [52]. Although NIRS cannot discriminate between myoglobin and hemoglobin $[53,54]$, the myoglobin contribution was discarded because no change in its concentration was expected during the experimental sessions. NIRS signals were collected from the frontal lobe.

Transcranial Doppler (TCD) ultrasound with $2 \mathrm{MHz}$ monitoring probe (Viasonix Dolphin IQ and 4D, Natanya, Israel) was used to measure unilateral cerebral flow velocity from the middle cerebral artery $(\mathrm{MCAv}, \mathrm{cm} / \mathrm{s})$ during all tasks. The probe was held in place by a 3D-printed custom-made helmet.

Cerebrovascular Reactivity $(\mathrm{CVR}, \mathrm{cm} / \mathrm{s} / \mathrm{mmHg})$ was computed as a ratio between task related changes in $\mathrm{MCAv}$ and $\mathrm{PeTCO}_{2}\left(\triangle \mathrm{MCAv} / \triangle \mathrm{PeTCO}_{2}\right)$, and Cerebrovascular Conductance Index $(\mathrm{CVCi}, \mathrm{cm} / \mathrm{s} / \mathrm{mmHg})$ was computed as a ratio between MCAv and ABP. While, $\triangle \mathrm{CVCi}$ is computed as $\left([\mathrm{MCAv} / \mathrm{ABP}]_{\mathrm{t}}-[\mathrm{MCAv} / \mathrm{ABP}]_{\mathrm{b}}\right)$; where $\mathrm{t}$ and $\mathrm{b}$ represents task and basal values, respectively.

All signal were continuously digitally sampled (Cambridge Electronic Design - CED Micro 1401, Cambridge, UK) at $100 \mathrm{~Hz}$ and stored on the computer. The Spike2 software (Version 9.14, CED, Cambridge, UK) was used for both data acquisition and analysis.

\subsection{Statistical analysis}

Statistical analysis was performed using MATLAB ${ }^{\circledR}$ Version R2021b (The MathWorks, Natick, Massachusetts, USA). After normality assessment (Kolmogorov-Smirnov test), the entire sample $\mathrm{HR}, \mathrm{ABP}, \mathrm{PETCO}_{2}, \mathrm{MCAv}$, TOI and $\mathrm{THI}$ were submitted to repeated measures ANOVA according to a 4 test (basal(b)-TMT, b-MAT, b-HVT, b-RBT) x 2 Condition ( $b$, task) experimental design. Post hoc analyses were performed through paired $t$ tests. Since sample size did not allow a reliable comparison between groups, ANOVA was repeated using SHSS scores as a covariate.

For the tasks showing changes of MCAv with respect to basal conditions, Spearman coefficients able to reveal nonlinear correlations and were computed between the averaged basal values of $\mathrm{MCAv}, \mathrm{ABP}$ and $\mathrm{PETCO}_{2}$. Assuming that $\mathrm{ABP}$ and $\mathrm{P}_{\mathrm{ETCO}} \mathrm{CO}_{2}$ were the 
systemic variables influencing MCAv, the changes in MCAv $(\triangle \mathrm{MCAv}), \mathrm{ABP}(\triangle \mathrm{ABP})$ and $\mathrm{PETCO}_{2}\left(\triangle \mathrm{PETCO}_{2}\right)$ occurring during tasks with respect to basal conditions were computed for the entire sample. The correlations of $\triangle \mathrm{MCAv}$ with $\triangle \mathrm{ABP}$ and $\triangle \mathrm{PETCO}_{2}$, and with the derived variables CVR and $\triangle \mathrm{CVCi}$ were computed. Moreover, the correlation between THI and TOI were computed for each test. Partial correlations controlling for hypnotizability were also performed, and successive within groups correlations were studied when the entire sample partial correlations revealed a moderation by hypnotizability. For all analyses, significance was set at $\mathrm{p}=.05$.

\section{Results}

Hypnotic assessment identified 11 lows (SHSS mean score \pm SD; $2 \pm 1.58$ ), 5 mediums $(6 \pm 1), 8$ highs $(8.5 \pm 0.71)$. Excluding the subject with SHSS score $=6$, the sample included 13 medium-lows (med-lows; SHSS range: 0-5; mean score \pm SD: $1.38 \pm 1.98$ ) and 10 medium-highs (med-highs; SHSS range: 7-12; mean score \pm SD: $8.1 \pm 0.73$ ).

On a numerical rating scale ranging from 0 (minimum) to 10 (maximum), the experienced cognitive fatigue during TMT and MAT tasks considered together (Mean \pm SD) was $6.5 \pm 0.63$ (med-lows: $6.27 \pm 0.63$; med-highs: $6.75 \pm 0.54$ ).

Systemic, Doppler and NIRS variables exhibited different changes during the four tasks with respect to basal conditions, which were not influenced by hypnotizability (Repeated measures ANOVA). Correlational analysis, in contrast, revealed hypnotizabilityrelated differences in the correlation of MCAv with arterial blood pressure (which was significant only in med-highs) and with $\mathrm{PETCO}_{2}$ (which was significant only in med-lows). Table 1 reports mean values and standard deviations of $\mathrm{HR}, \mathrm{ABP}, \mathrm{PeTCO}_{2}, \mathrm{MCAv}$, TOI and THI.

Table 1. Variables mean values and standard deviation

\begin{tabular}{|c|c|c|c|c|c|}
\hline \multirow{2}{*}{$\begin{array}{l}\text { Condition } \\
T M T \\
\end{array}$} & \multirow[t]{2}{*}{ Variable } & \multicolumn{2}{|c|}{ med-lows } & \multicolumn{2}{|c|}{ med-highs } \\
\hline & & Mean & SD & Mean & SD \\
\hline \multirow[t]{6}{*}{ Basal } & HR (bpm) & 72.02 & 12.08 & 78.50 & 14.66 \\
\hline & $\mathrm{ABP}(\mathrm{mmHg})$ & 82.29 & 17.23 & 80.71 & 14.66 \\
\hline & $\mathrm{P}_{\mathrm{ETCO}}(\mathrm{mmHg})$ & 37.31 & 1.91 & 34.63 & 3.45 \\
\hline & $\operatorname{MCAv}(\mathrm{cm} / \mathrm{s})$ & 59.52 & 9.61 & 52.13 & 10.43 \\
\hline & TOI (\%) & 71.39 & 4.77 & 71.83 & 5.85 \\
\hline & THI (a.u.) & 1.02 & 0.11 & 0.98 & 0.05 \\
\hline \multirow[t]{6}{*}{ Task } & $\mathrm{HR}^{*}(\mathrm{bpm})$ & 79.09 & 13.66 & 81.62 & 14.46 \\
\hline & $\mathrm{ABP}^{*}(\mathrm{mmHg})$ & 87.95 & 14.72 & 86.56 & 13.98 \\
\hline & $\mathrm{P}_{\mathrm{ETCO}}(\mathrm{mmHg})$ & 37.13 & 1.40 & 34.46 & 3.43 \\
\hline & $\operatorname{MCAv}(\mathrm{cm} / \mathrm{s})$ & 59.02 & 10.10 & 50.18 & 9.87 \\
\hline & TOI (\%) & 71.87 & 4.94 & 71.96 & 5.71 \\
\hline & THI (a.u.) & 1.02 & 0.11 & 1.01 & 0.07 \\
\hline \multicolumn{6}{|l|}{$M A T$} \\
\hline \multirow[t]{6}{*}{ Basal } & HR (bpm) & 75.98 & 11.61 & 76.50 & 14.10 \\
\hline & $\mathrm{ABP}(\mathrm{mmHg})$ & 78.19 & 14.59 & 83.71 & 15.15 \\
\hline & $\mathrm{P}_{\text {етCO}}(\mathrm{mmHg})$ & 36.51 & 1.92 & 34.53 & 3.29 \\
\hline & MCAv (cm/s) & 60.25 & 8.70 & 52.56 & 10.61 \\
\hline & TOI (\%) & 71.38 & 5.68 & 72.21 & 5.79 \\
\hline & THI (a.u.) & 1.03 & 0.12 & 1.02 & 0.15 \\
\hline Task & $\mathrm{HR}^{*}(\mathrm{bpm})$ & 84.20 & 12.41 & 84.51 & 15.00 \\
\hline
\end{tabular}




\begin{tabular}{|c|c|c|c|c|c|}
\hline & $\mathrm{ABP}^{*}(\mathrm{mmHg})$ & 88.64 & 12.91 & 96.89 & 9.80 \\
\hline & $\mathrm{PetCO}_{2}(\mathrm{mmHg})$ & 36.96 & 2.61 & 34.91 & 3.68 \\
\hline & $\operatorname{MCAv}(\mathrm{cm} / \mathrm{s})$ & 61.60 & 10.27 & 55.66 & 11.87 \\
\hline & TOI (\%) & 71.48 & 4.00 & 72.91 & 6.05 \\
\hline & THI (a.u.) & 1.01 & 0.11 & 1.03 & 0.16 \\
\hline \multicolumn{6}{|l|}{$H V T$} \\
\hline \multirow[t]{6}{*}{ Basal } & HR (bpm) & 72.93 & 10.09 & 77.88 & 11.36 \\
\hline & $\mathrm{ABP}(\mathrm{mmHg})$ & 85.65 & 12.47 & 83.03 & 14.77 \\
\hline & $\mathrm{PeTCO}_{2}(\mathrm{mmHg})$ & 33.61 & 2.49 & 32.21 & 3.73 \\
\hline & $\operatorname{MCAv}(\mathrm{cm} / \mathrm{s})$ & 61.25 & 7.24 & 59.68 & 6.67 \\
\hline & TOI (\%) & 69.41 & 5.61 & 71.41 & 5.81 \\
\hline & THI (a.u.) & 0.99 & 0.11 & 1.02 & 0.16 \\
\hline \multirow[t]{6}{*}{ Task } & $\mathrm{HR}^{*}(\mathrm{bpm})$ & 99.34 & 19.71 & 84.12 & 13.01 \\
\hline & $\mathrm{ABP}(\mathrm{mmHg})$ & 83.58 & 12.93 & 82.53 & 10.65 \\
\hline & $\mathrm{PeTCO}_{2}{ }^{*}(\mathrm{mmHg})$ & 18.34 & 1.46 & 17.92 & 1.59 \\
\hline & $\operatorname{MCAv}^{*}(\mathrm{~cm} / \mathrm{s})$ & 34.19 & 7.07 & 33.35 & 5.17 \\
\hline & TOI $^{*}(\%)$ & 67.45 & 4.94 & 70.50 & 6.12 \\
\hline & THI (a.u.) & 0.98 & 0.11 & 1.02 & 0.15 \\
\hline \multicolumn{6}{|l|}{$R B T$} \\
\hline \multirow[t]{6}{*}{ Basal } & HR (bpm) & 74.26 & 9.36 & 76.77 & 11.24 \\
\hline & $\mathrm{ABP}(\mathrm{mmHg})$ & 78.35 & 12.82 & 85.23 & 11.25 \\
\hline & $\mathrm{PetCO}_{2}(\mathrm{mmHg})$ & 38.15 & 4.47 & 35.96 & 4.05 \\
\hline & $\operatorname{MCAv}(\mathrm{cm} / \mathrm{s})$ & 58.38 & 6.51 & 56.53 & 9.58 \\
\hline & $\mathrm{TOI}^{*}(\%)$ & 70.51 & 5.51 & 71.34 & 5.87 \\
\hline & THI (a.u.) & 1.01 & 0.11 & 1.02 & 0.16 \\
\hline \multirow[t]{6}{*}{ Task } & $\mathrm{HR}^{*}(\mathrm{bpm})$ & 87.52 & 11.91 & 87.57 & 13.70 \\
\hline & $\mathrm{ABP}^{*}(\mathrm{mmHg})$ & 88.47 & 11.57 & 95.33 & 17.84 \\
\hline & $\mathrm{PeTCO}_{2}{ }^{*}(\mathrm{mmHg})$ & 48.12 & 3.13 & 46.08 & 3.22 \\
\hline & $\operatorname{MCAv}^{*}(\mathrm{~cm} / \mathrm{s})$ & 82.71 & 13.50 & 75.59 & 11.53 \\
\hline & $\mathrm{TOI}^{*}(\%)$ & 72.33 & 3.67 & 73.10 & 4.40 \\
\hline & THI (a.u.) & 1.03 & 0.15 & 1.07 & 0.16 \\
\hline
\end{tabular}

Note: *, statistically significant differences between basal and task conditions in the entire sample.

\subsection{Repeated measures ANOVA}

\subsubsection{Systemic measures}

HR exhibited a significant test $x$ condition interaction $\left(F(3,69)=7.511, p=.002, \eta^{2}=.246\right.$, $\alpha=.982$ ) whose decomposition revealed significant increases during tasks for all tests (TMT, $\mathrm{t}=4.561$; MAT, $\mathrm{t}=4.895$; HVT, $\mathrm{t}=5.048$ and RBT, $\mathrm{t}=8.306$; $\mathrm{p}=.0001$ ). It survived after controlling for SHSS scores and was sustained by larger values during HVT than during $\operatorname{MAT}(\mathrm{t}=2.138, \mathrm{p}=.043)$ and TMT $(\mathrm{t}=3.242, \mathrm{p}=.004)$.

For ABP, ANOVA revealed a significant test $x$ condition interaction $(F(3,69)=218.26$, $\left.\mathrm{p}=.0001, \eta^{2}=.905, \alpha=1.00\right)$, surviving after controlling for SHSS scores. Its decomposition showed significant differences between basal and task condition for TMT $(t(1,23)=3.27$, $\mathrm{p}=.003)$, MAT $(\mathrm{t}=6.47, \mathrm{p}=.0001)$ and RBT $(\mathrm{t}=4.25, \mathrm{p}=.0001)$, but not for HVT. 
$\mathrm{PeTCO}_{2}$ exhibited a significant test $x$ condition interaction $(\mathrm{F}(3,69)=566.28, \mathrm{p}=.0001$, $\left.\eta^{2}=.961, \alpha=1.00\right)$, which remained significant after controlling for SHSS scores. Decomposition revealed significant basal vs task differences for HVT ( $t=24.18, p=.0001)$ and RBT $(\mathrm{t}=18.73$, $\mathrm{p}=.0001)$ only.

Average response curves to hyperventilation (HVT) and rebreathing (RBT) with standard deviation for $\mathrm{PeTCO}_{2}$, TOI, MCAv and ABP are shown in Figure 1.

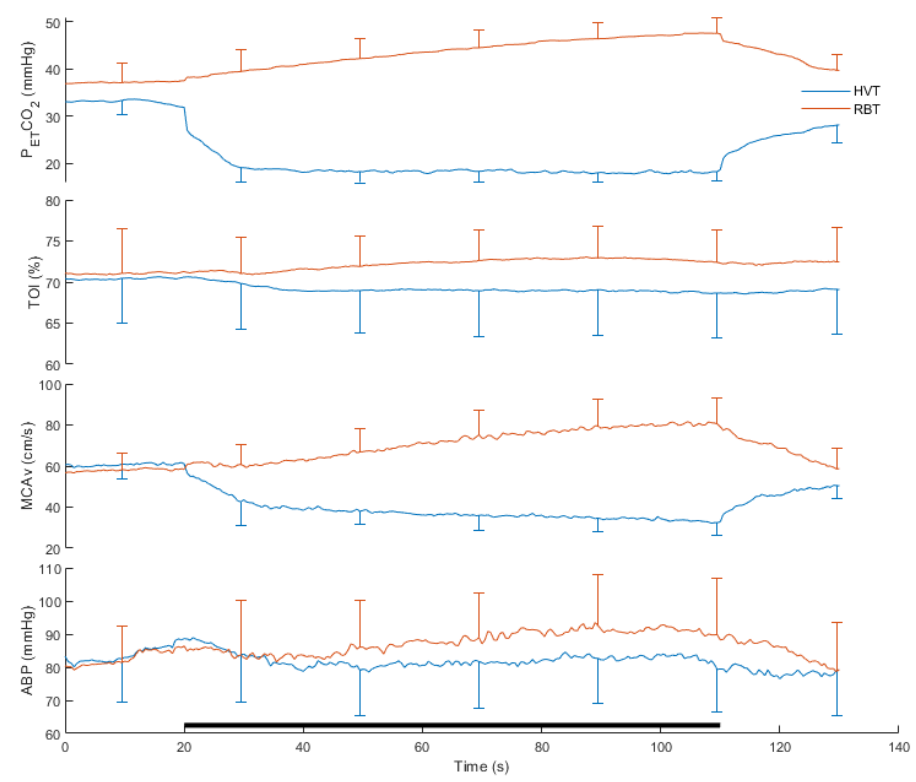

Figure 1. Average response curves to hyperventilation (HVT) and rebreathing (RBT) with standard deviation for the different variables. $\mathrm{PeTCO}_{2}$ : partial pressure of end-tidal $\mathrm{CO}_{2}$; TOI: tissue oxygenation index; MCAv: middle cerebral artery flow velocity; and ABP: arterial blood pressure. The black bar at the bottom indicates the duration of the task. Note the opposite effects on each variable exhibited by the HVT and RBT.

\subsubsection{Doppler measures}

MCAv exhibited a significant test $x$ condition interaction $(F(3,69)=217.48, p=.0001$, $\left.\eta^{2}=.904, \alpha=1.00\right)$, which remained significant considering SHSS as a covariate. As shown in Figure 2, its decomposition revealed a significant difference between basal and task condition for HVT $\mathrm{t}(1,23)=24.91, \mathrm{p}=.0001)$ and RBT $(\mathrm{t}=12.58, \mathrm{p}=.0001)$ only.

For the derived variable $\triangle \mathrm{CVCi}$, the significant test $\mathrm{x}$ condition interaction $\left(\mathrm{F}(3,69)=73,30, \mathrm{p}=.0001, \eta^{2}=.761, \alpha=1.00\right)$, which survived after controlling for hypnotizability, was sustained by a significant difference between basal and task condition in all tests (TMT, $\mathrm{t}=2.93, \mathrm{p}=.008$; MAT, $\mathrm{t}=3.51, \mathrm{p}=.002$; HVT, $\mathrm{t}=16.48, \mathrm{p}=.0001$; and $\mathrm{RBT}, \mathrm{t}=6.98$, $\mathrm{p}=.0001)$. 

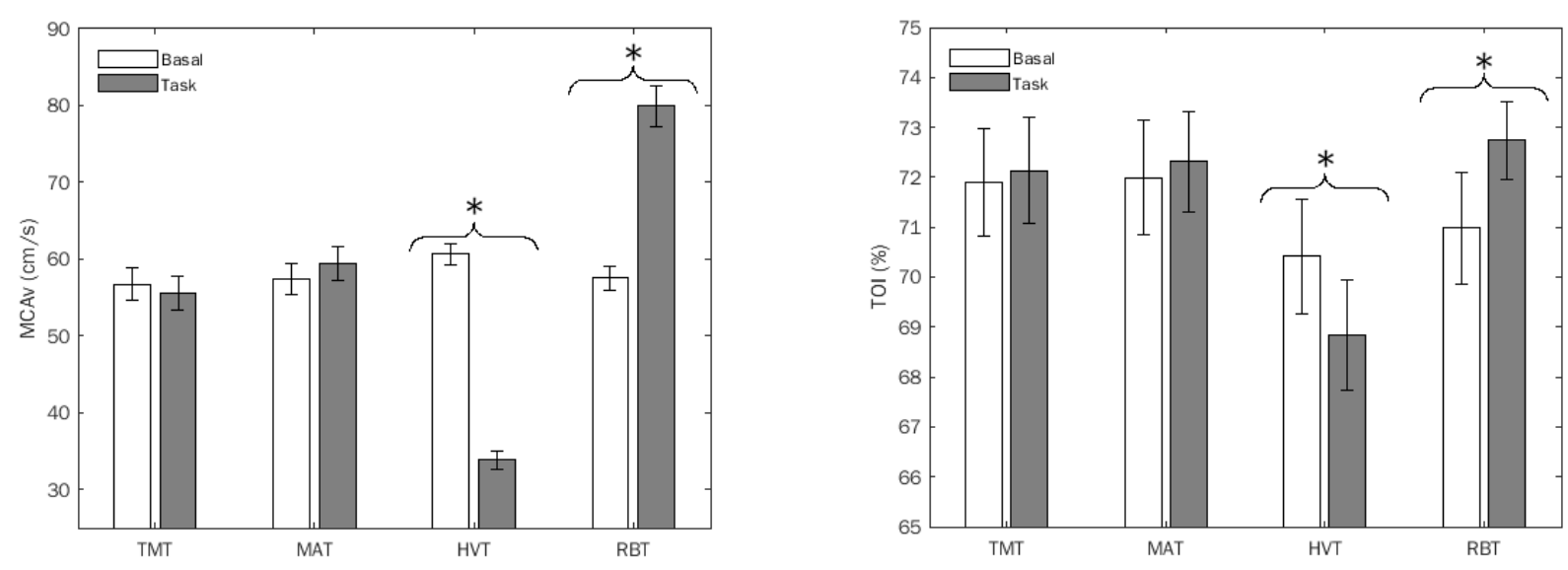

Figure 2. Middle cerebral artery flow velocity (MCAv) and tissue oxygenation index (TOI) (Mean, SEM) of the entire sample. TMT: trail making task; MAT: mental arithmetic task; HVT: hyperventilation; RBT: rebreathing. *, statistically significant differences.

\subsubsection{NIRS measures}

In Figure 2, TOI exhibited a significant test $x$ condition interaction $(F(3,69)=15.98$, $\mathrm{p}=.0001, \eta^{2}=.410, \alpha=1.00$ ), which survived after controlling for SHSS scores. Its decomposition revealed significant differences between basal and task conditions for HVT ( $\mathrm{t}=4.68$, $\mathrm{p}=.0001)$ and RBT ( $\mathrm{t}=3.70, \mathrm{p}=.001)$ only.

THI did not exhibit any significant difference between basal and task conditions. They were not disclosed by controlling for hypnotizability.

\subsection{Correlational analyses}

Since MCAv did not exhibit significant differences between basal and experimental conditions in TMT and MAT, further analyses were conducted only on HVT and RBT.

Preliminary analyses performed on the averaged basal values of HVT and RBT re-

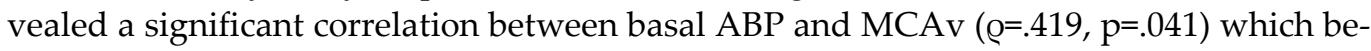
came non-significant controlling for hypnotizability, and no correlation of $\triangle \mathrm{MCAv}$ with $\triangle \mathrm{PETCO}_{2}$. Within groups analyses indicated a significant correlation of $\triangle \mathrm{MCAv}$ with $\triangle \mathrm{ABP}$ only in med-lows ( $\mathrm{Q}=.619, \mathrm{p}=.014)$ and did not disclose a correlation between $\Delta \mathrm{M}$ $\mathrm{CAv}$ and $\triangle \mathrm{PETCO}_{2}$.

For HVT, Spearman coefficient computed on $\triangle \mathrm{MCAv}, \triangle \mathrm{ABP}$, and $\triangle \mathrm{P}_{\mathrm{ET}} \mathrm{CO}_{2}$ on the entire sample indicated a significant correlation between $\triangle \mathrm{MCAv}$ and $\triangle \mathrm{P}_{\mathrm{ETCO}}(\mathrm{Q}=.484$, $\mathrm{p}=.017$ ), which became non-significant after removing the effects of hypnotizability by partial correlation. Successive within group analyses revealed a significant correlation between $\triangle \mathrm{MCAv}$ and $\triangle \mathrm{PeTCO}_{2}(\mathrm{Q}=.606, \mathrm{p}=.028)$ and a significant correlation of $\triangle \mathrm{MCAv}$ with $\triangle \mathrm{ABP}(\mathrm{Q}=.842, \mathrm{p}=.002)$.in med-highs (Figure 3). 

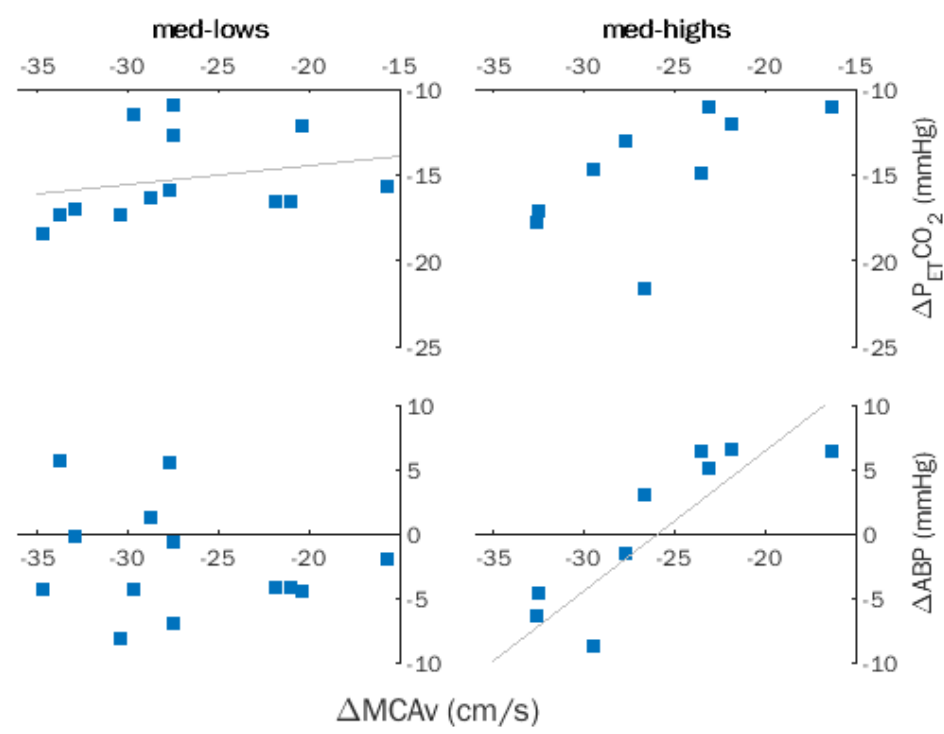

Figure 3. Hyperventilation (HVT). Within groups correlations between changes in middle cerebral artery flow velocity (MCAv), partial pressure of end-tidal $\mathrm{CO}_{2}\left(\mathrm{PeTCO}_{2}\right)$, and arterial blood pressure $(\mathrm{ABP})$ in med-lows and med-highs. Trendlines indicate significant correlations.

For RBT, no significant correlation between $\triangle \mathrm{MCAv}, \triangle \mathrm{ABP}, \triangle \mathrm{P}_{\mathrm{ET}} \mathrm{CO}_{2}$ was observed in the entire sample and was disclosed after removing the effects of hypnotizability (Figure 4).

Spearman correlation was also computed on $\triangle \mathrm{MCAv}$ and the derived variables CVR and $\triangle \mathrm{CVCi}$ whose mean values are reported in Table 2 . In the entire sample of HVT, the

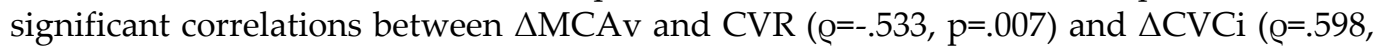
$\mathrm{p}=.002$ ) became non-significant after removing the effects of hypnotizability. Indeed, in HVT only med-lows, exhibited significant correlations of $\triangle \mathrm{MCAv}$ with CVR ( $\mathrm{Q}=-.602$, $\mathrm{p}=.020)$ and $\triangle \mathrm{CVCi}(\mathrm{Q}=.861, \mathrm{p}=.0001)$.
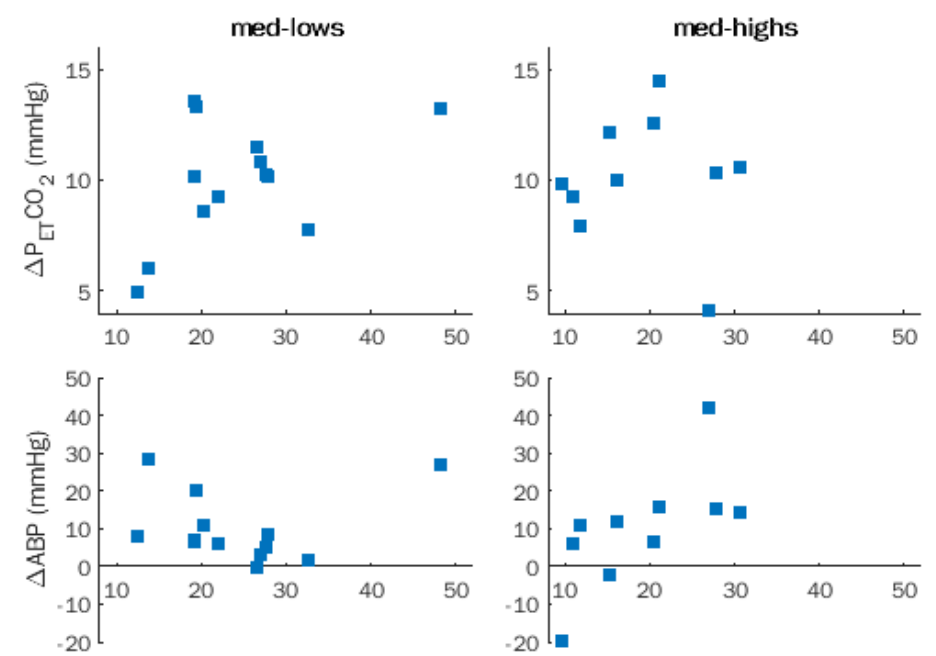

$\triangle \operatorname{MCAv}(\mathrm{cm} / \mathrm{s})$

Figure 4. Rebreathing (RBT). Within groups correlations between changes in middle cerebral artery flow velocity $(\mathrm{MCAv})$, partial pressure of end-tidal $\mathrm{CO}_{2}\left(\mathrm{PeTCO}_{2}\right)$, and arterial blood pressure (ABP) in med-lows and med-highs. 
Table 2. Derived Doppler variables

\begin{tabular}{|c|c|c|c|c|c|}
\hline \multirow[t]{2}{*}{ Task } & \multirow[t]{2}{*}{ Variable } & \multicolumn{2}{|c|}{ med-lows } & \multicolumn{2}{|c|}{ med-highs } \\
\hline & & Mean & SD & Mean & SD \\
\hline \multirow[t]{2}{*}{$H V T$} & $\triangle \mathrm{CVCi}(\mathrm{cm} / \mathrm{s} / \mathrm{mmHg})$ & -0.32 & 0.12 & -0.33 & 0.07 \\
\hline & $\mathrm{CVR}(\mathrm{cm} / \mathrm{s} / \mathrm{mmHg})$ & 1.81 & 0.46 & 1.91 & 0.49 \\
\hline \multirow[t]{2}{*}{$R B T$} & $\triangle \mathrm{CVCi}(\mathrm{cm} / \mathrm{s} / \mathrm{mmHg})$ & 0.18 & 0.12 & 0.16 & 0.13 \\
\hline & CVR $(\mathrm{cm} / \mathrm{s} / \mathrm{mmHg})$ & 2.49 & 0.76 & 2.17 & 1.66 \\
\hline
\end{tabular}

Note: CVCi: cerebrovascular conductance index; CVR: cerebrovascular reactivity.

In RBT, $\triangle$ MCAv was significantly correlated only CVR ( $\varrho=.818, p=.0001)$, and the correlation survived after removing the effects of hypnotizability $(\varrho=.629, \mathrm{p}=.001)$.

During hyperventilation (Figure 5), CVR and $\triangle \mathrm{CVCi}$ were significantly correlated

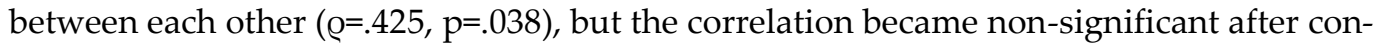
trolling for hypnotizability. A significant correlation remained significant only in medlows ( $\mathrm{Q}=.736, \mathrm{p}=.004)$. During rebreathing (Figure 5), CVR and $\triangle \mathrm{CVCi}$ were not significantly correlated between each other. Nonetheless, controlling for hypnotizability disclosed a significant correlation in med-lows ( $\mathrm{Q}=.626, \mathrm{p}=.022)$.

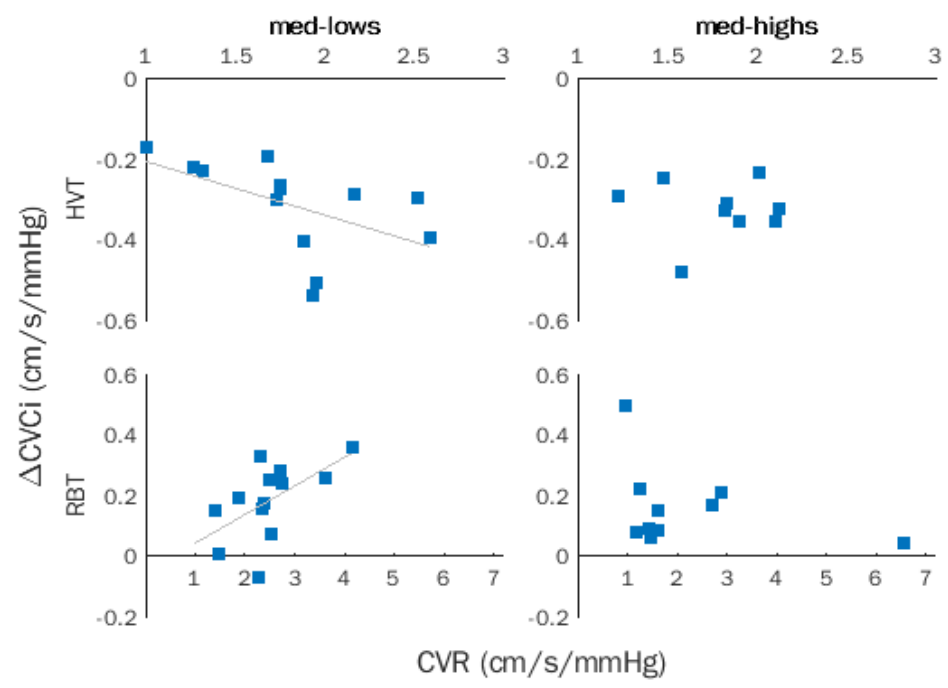

Figure 5. Cerebrovascular reactivity and cerebrovascular conductance index. Within groups correlations between CVR $(\mathrm{cm} / \mathrm{s} / \mathrm{mmHg})$ and $\triangle \mathrm{CVCi}(\mathrm{cm} / \mathrm{s} / \mathrm{mmHg})$. HVT: hyperventilation; RBT: rebreathing. Trendlines indicate significant correlations in med-lows.

\subsubsection{NIRS variables}

No significant correlation between $\triangle \mathrm{MCAv}$ and $\triangle \mathrm{TOI}$ or $\triangle \mathrm{THI}$ was observed in HVT and was disclosed after controlling for hypnotizability. In RBT, a significant correlation was found between $\triangle \mathrm{MCAv}$ and $\triangle \mathrm{TOI}(\mathrm{Q}=.514, \mathrm{p}=.010)$. It became borderline significant after controlling for hypnotizability $(\mathrm{p}=.057)$. Successive within group analyses, in fact, revealed a significant correlation only in med-lows $(\mathrm{Q}=.570, \mathrm{p}=.042)$. 


\section{Discussion}

Our study was motivated by the observation of different brachial artery post-occlusion FMD in lows and highs. In the latter, FMD was scarcely and not influenced by nociceptive stimulation and mental stress, respectively, in contrast to lows who behave like the general population $[13,14]$ displaying decreased FMD. We wondered whether hypnotizability-related differences may occur also in the cerebrovascular responses to physical and mental stimulation.

\subsection{Repeated measures ANOVA}

The absence of significant changes in blood flow velocity during cognitive tasks in both groups contrasts with other authors' findings reporting increased blood flow with increasing cognitive load in the general population [55]. However, Csipo et al. employed a visual text inspection task with high time pressure (a new task every $2 \mathrm{~s}$ ); the methodological differences could account for different results. In addition, the discrepancy may be due to the characteristics of the studied sample which does not reflect the distribution of hypnotizability in the general population [56]. The absence of increases in the middle cerebral artery blood flow, despite significant increases in systemic blood pressure, can be accounted for by the pre-eminent local control of cerebral blood flow. The similar results of med-lows and med-highs could be due to their different cognitive abilities, as medlows may have paid poor attention to the tasks, and med-highs may have experienced low cognitive effort $[9,43,45]$. Thus, scarce neural engagement and, consequently, scarce increase in metabolism may have taken place in both groups.

Contrary to the expectation we did not observe increased oxygenation, indicative of an increased cortical activity, during the mental stress tasks. This type of hemodynamic changes is increasingly investigated as a possible sign of mental activation to be employed as a communication signal in brain-computer interfaces [57]. Recent studies based on the use of multichannel NIRS monitoring (fNIRS), which yields a spatial mapping of cortical activation (although based on Beer-Lambert (B-L) variables) have evidenced pattern of focal activation (increased oxygenation), possibly associated with depression of neighboring cortical areas (decreased oxygenation) [58,59]. Lack of a net TOI change in the present study could be explained by a non-optimal location of the NIRS probe.

On the other hand, the standard Beer-Lambert (B-L) NIRS variables, such as oxygenated and deoxygenated hemoglobin concentrations may suffer of relevant contamination from the most superficial (extracranial) tissue layers, as compared to variables derived from spatially-resolved spectroscopy (SRS), such as TOI and THI [60-62]. This possibility remains largely overlooked but is particularly insidious when analyzing tasks associated with autonomic activations, that may profoundly affect the circulation in cutaneous tissues of the head. This confounding factor has been held responsible for inconsistent effects of $\mathrm{CO}_{2}$ challenges on B-L NIRS variables [63]. Conversely, the SRS variables were shown to be quite independent of extracranial circulation, providing consistent changes in response to hyperventilation and rebreathing $[64,65]$. A clear response pattern was also observed here, with a significant TOI increase and decrease during rebreathing and hyperventilation, respectively.

Present findings confirm that, in the entire sample, hyperventilation and rebreathing induce decrease and increase in middle cerebral artery flow velocity and tissue oxygenation, respectively [66]. These responses occur in the presence of significant changes in ABP only during rebreathing and in $\mathrm{P}_{\mathrm{ETCO}} \mathrm{CO}_{2}$ during both rebreathing and hyperventilation and are not moderated by hypnotizability.

Even in the absence of significant differences between med-lows and med-highs in the mean values of $\mathrm{ABP}, \mathrm{PeTCO}_{2}$ and $\mathrm{MCAv}$ during tasks, however, the task-related changes in these variables could be differentially associated between each other in the two groups, suggesting different mechanisms. 


\subsection{Correlational analyses}

Hypnotizability, in fact, moderates the correlation of the changes in blood flow velocity with those in $\mathrm{PETCO}_{2}$ and $\mathrm{ABP}$; and within groups correlational analyses reveals different relevance of the chemical and mechanical stimulation to the med-lows' and the med-highs' cerebral blood flow velocity.

During hyperventilation, a major role for arterial blood pressure in med-highs and for $\mathrm{PETCO}_{2}$ in med-lows in the control of cerebral blood flow velocity can be hypothesized. Not alternatively, a different interaction between $\mathrm{PЕTCO}_{2}$ and ABP [37] may be involved.

The absence of $\mathrm{ABP}$ changes during hyperventilation does not allow to exclude those non-significant decreases in arterial pressure may have influenced the med-highs' cerebral blood flow, as their $\triangle \mathrm{MCAv}$ was correlated with $\triangle \mathrm{ABP}$ during the task but not in basal conditions. An opposite behavior occurs in med-lows who exhibit a significant association between $\triangle \mathrm{ABP}$ and $\triangle \mathrm{MCAv}$ in basal, but not during hyperventilation. In medlows the association of $\triangle \mathrm{MCAv}$ with $\triangle \mathrm{P}_{\mathrm{ETCO}}$ is consistent between basal conditions and hyperventilation and supports the hypothesis that a major role of chemical stimulation and/or a different interaction between $\mathrm{ABP}$ and $\mathrm{PeTCO}_{2}[37$ ] in these participants.

Theoretically, the decrease in MCAv observed in med-highs during hyperventilation despite scarce changes in ABP, could be sustained by the sensitivity of their vessels muscle cells to blood pressure. The preferential effect of $\mathrm{NO}$ on precapillary sphincters and pericytes rather than on smooth muscle cells [67] may have contributed to the observed changes in MCAv. The lack of significant correlation between $\triangle \mathrm{MCAv}$ and $\triangle \mathrm{P}_{\mathrm{ETCO}} \mathrm{CO}_{2}$ curring in both groups during rebreathing may be due to $\mathrm{CO}_{2}$ ceiling effect.

During both hyperventilation and rebreathing an association of cerebrovascular reactivity (CVR, related to $\left.\mathrm{PETCO}_{2}\right)$ and cerebrovascular conductance index $(\mathrm{CVCi}$, related to ABP) was found only in med-lows. We argue that a different interaction between arterial blood pressure and $\mathrm{CO}_{2}$ [37] occurs in med-highs and med-lows. Moreover, in HVT the correlation between changes in cerebral blood volume (THI) and tissue oxygenation (TOI) observed in med-lows, but not in med-highs, suggests different metabolic requests.

\section{Limitations and Conclusions}

This study has a few limitations. One is the small sample size which did not allow a direct comparison between highs, lows (each representing $15 \%$ of the general population) and mediums which represent its largest part (70\%) [56]. In a few tasks, in fact, highs or lows may behave like mediums [12]. Another limitation is the absence of very highly hypnotizable persons in the studied sample (the maximum SHSS score was 9 out of 12). Thus, the present study should be repeated in a larger sample including lows, mediums and highs. Moreover, hemogas analyses could reflect blood $\mathrm{CO}_{2}$ better than end-tidal measures and could be more reliably associated with NIRS measures. Finally, given the complexity of the cerebrovascular control, recent approaches based on the complexity of the arterial pressure and cerebral blood flow time series may allow to better detect relationships between these two variables [68].

Present findings do not allow to exclude that med-highs may exhibit a different association between $\mathrm{ABP}, \mathrm{PETCO}_{2}$ and cerebral blood flow with respect to med-lows also when $\mathrm{ABP}$ increases. In this respect, it may be interesting that more frequent increases in systemic blood pressure are likely to occur in highs than in lows owing to their greater emotional intensity, empathy $[69,70]$ and interoceptive sensitivity $[12,69]$. In addition, changes in synaptic glutamate due to tasks could induce increases in the astrocyte's calcium mediated dilatory action independently from systemic blood pressure [71]. Since highs respond to cognitive tasks with larger glutamatergic cortical activity [72], they might be more prone than lows to undergo astrocytes dependent NO release in the everyday life. Thus, the hypothesis that the earlier observed highs' reduced cerebral grey matter volume $[4,5]$ can be due to the toxic effects of too large NO availability during environmental stimulation cannot be excluded. 
In conclusion, this is the first assessment of hypnotizability-related differences in the mechanisms controlling cerebral blood flow, cerebrovascular reactivity and conductance in response to hyperventilation and rebreathing, given the med-highs preferential response to arterial blood pressure, the med-lows apparently better response to $\mathrm{CO}_{2}$ and the different interaction between cerebrovascular conductance and reactivity in the two groups. In a general perspective, the findings support the view that hypnotizability is associated with physiological correlates influencing the everyday life independently from suggestions and induction of the hypnotic state [2,73].

Author Contributions: Conceptualization, A.R., E.L.S. and S.R.; Methodology, A.R., E.L.S. and S.R; Formal Analysis, E.S.; Investigation, A.R. and E.L.S.; Resources, S.R.; Data Curation, A.R.; Writing - Original Draft Preparation, A.R. and E.L.S.; Writing - Review \& Editing, E.L.S. and S.R.; Visualization, A.R. and E.L.S.; Supervision, S.R.; Funding Acquisition, E.L.S., and S.R.

Funding: This study was supported by Ministero dell'Istruzione, dell'Università e della Ricerca (MIUR) under the programme "Dipartimenti di Eccellenza ex L.232/2016" to the Dipartimento di Neuroscienze "Rita Levi Montalcini", Università degli Studi di Torino (UNITO). A.R. was supported by a Doctoral Fellowship funded by the Partnership for Knowledge (PfK) programme of the Agenzia Italiana per la Cooperazione allo Sviluppo (AICS) under the umbrella of the Ministero degli Affari Esteri e della Cooperazione Internazionale (MAECI), Italy.

Institutional Review Board Statement: The study was carried out in accordance with the Declaration of Helsinki and was approved by the Institutional Ethical Committee of the University of Torino (\# 219859, issued on April 8, 2021).

Informed Consent Statement: All subjects signed informed consent for hypnotic assessment and utilization of their recordings performed 2 months earlier (during a short period of availability of the entire instrumentation) for the present study. Written informed consent has been obtained from all subjects to publish this paper.

Data Availability Statement: Data available upon request.

Acknowledgments: The authors are grateful to Raffaele Pertusio for technical assistance.

Conflicts of Interest: The authors declare no conflict of interest. 


\section{References}

1. Elkins, G.R.; Barabasz, A.F.; Council, J.R.; Spiegel, D. Advancing Research and Practice: The Revised APA Division 30 Definition of Hypnosis. Int. J. Clin. Exp. Hypn. 2015, 63, 1-9, doi:10.1080/00207144.2014.961870.

2. Santarcangelo, E.L.; Scattina, E. Complementing the Latest APA Definition of Hypnosis: SensoryMotor and Vascular Peculiarities Involved in Hypnotizability. Int. J. Clin. Exp. Hypn. 2016, 64, 318 330, doi:10.1080/00207144.2016.1171093.

3. Piccione, C.; Hilgard, E.R.; Zimbardo, P.G. On the Degree of Stability of Measured Hypnotizability Over a 25-Year Period. J. Pers. Soc. Psychol. 1989, 56, 289-295, doi:10.1037//0022-3514.56.2.289.

4. Landry, M.; Lifshitz, M.; Raz, A. Brain Correlates of Hypnosis: A Systematic Review and MetaAnalytic Exploration. Neurosci. Biobehav. Rev. 2017, 81, 75-98, doi:10.1016/j.neubiorev.2017.02.020.

5. Picerni, E.; Santarcangelo, E.L.; Laricchiuta, D.; Cutuli, D.; Petrosini, L.; Spalletta, G.; Piras, F. Cerebellar Structural Variations in Subjects with Different Hypnotizability. The Cerebellum 2019, 18, 109-118, doi:10.1007/s12311-018-0965-y.

6. Raz, A. Attention and Hypnosis: Neural Substrates and Genetic Associations of Two Converging Processes. Int. J. Clin. Exp. Hypn. 2005, 53, 237-58, doi:10.1080/00207140590961295.

7. Cojan, Y.; Waber, L.; Schwartz, S.; Rossier, L.; Forster, A.; Vuilleumier, P. The Brain under SelfControl: Modulation of Inhibitory and Monitoring Cortical Networks during Hypnotic Paralysis. Neuron 2009, 62, 862-75, doi:10.1016/j.neuron.2009.05.021.

8. McGeown, W.J.; Mazzoni, G.; Vannucci, M.; Venneri, A. Structural and Functional Correlates of Hypnotic Depth and Suggestibility. Psychiatry Res. Neuroimaging 2015, 231, 151-159, doi:10.1016/j.pscychresns.2014.11.015.

9. Ibáñez-Marcelo, E.; Campioni, L.; Phinyomark, A.; Petri, G.; Santarcangelo, E.L. Topology Highlights Mesoscopic Functional Equivalence between Imagery and Perception: The Case of Hypnotizability. Neuroimage 2019, 200, 437-449, doi:10.1016/j.neuroimage.2019.06.044.

10. Spina, V.; Chisari, C.; Santarcangelo, E.L. High Motor Cortex Excitability in Highly Hypnotizable Individuals: A Favourable Factor for Neuroplasticity? Neuroscience 2020, 430, 125-130, doi:10.1016/j.neuroscience.2020.01.042.

11. Rosati, A.; Belcari, I.; Santarcangelo, E.L.; Sebastiani, L. Interoceptive Accuracy as a Function of Hypnotizability. Int. J. Clin. Exp. Hypn. 2021, 1-12, doi:10.1080/00207144.2021.1954859.

12. Diolaiuti, F.; Huber, A.; Ciaramella, A.; Santarcangelo, E.L.; Sebastiani, L. Hypnotisability-related Interoceptive Awareness and Inhibitory/Activating Emotional Traits. Arch. Ital. Biol. 2019, 157, 111119, doi:10.12871/00039829202042.

13. Jambrik, Z.; Santarcangelo, E.L.; Rudisch, T.; Varga, A.; Forster, T.; Carli, G. Modulation of paininduced endothelial dysfunction by hypnotizability. Pain 2005, 116, 181-186, doi:10.1016/j.pain.2005.03.041.

14. Jambrik, Z.; Santarcangelo, E.L.; Ghelarducci, B.; Picano, E.; Sebastiani, L. Does hypnotizability modulate the stress-related endothelial dysfunction? Brain Res. Bull. 2004, 63, 213-216, doi:10.1016/j.brainresbull.2004.01.011.

15. Jambrik, Z.; Chunzeng, L.; Santarcangelo, E.L.; Sebastiani, L.; Ghelarducci, B.; Picano, E. Traditional acupuncture does not modulate the endothelial dysfunction induced by mental stress. Int. J. Cardiovasc. Imaging 2004, 20, 357-362, doi:10.1023/B:CAIM.0000041939.61963.b0.

16. Hu, Y.; Chen, M.; Wang, M.; Li, X. Flow-Mediated Vasodilation through Mechanosensitive G Protein- 
Coupled Receptors in Endothelial Cells. Trends Cardiovasc. Med. 2021, doi:10.1016/j.tcm.2020.12.010.

17. Contestabile, A. Role of Nitric Oxide in Cerebellar Development and Function: Focus on Granule Neurons. Cerebellum 2012, 11, 50-61, doi:10.1007/s12311-010-0234-1.

18. Fantini, S.; Sassaroli, A.; Tgavalekos, K.T.; Kornbluth, J. Cerebral Blood Flow and Autoregulation: Current Measurement Techniques and Prospects for Noninvasive Optical Methods. Neurophotonics 2016, 3, 031411-31, doi:10.1117/1.NPh.3.3.031411.

19. Severinghaus, J.W.; Lassen, N. Step Hypocapnia to Separate Arterial from Tissue PCO2 in the Regulation of Cerebral Blood Flow. Circ. Res. 1967, 20, 272-8, doi:10.1161/01.res.20.2.272.

20. Fathi, A.R.; Yang, C.; Bakhtian, K.D.; Qi, M.; Lonser, R.R.; Pluta, R.M. Carbon dioxide influence on nitric oxide production in endothelial cells and astrocytes: Cellular mechanisms. Brain Res. 2011, 1386, 50, doi:10.1016/J.BRAINRES.2011.02.066.

21. Hoiland, R.L.; Fisher, J.A.; Ainslie, P.N. Regulation of the Cerebral Circulation by Arterial Carbon Dioxide. Compr. Physiol. 2019, 9, 1101-1154, doi:10.1002/cphy.c180021.

22. Caldwell, H.G.; Howe, C.A.; Hoiland, R.L.; Carr, J.M.J.R.; Chalifoux, C.J.; Brown, C. V; Patrician, A.; Tremblay, J.C.; Panerai, R.B.; Robinson, T.G.; et al. Alterations in Arterial CO2 rather than pH affect the Kinetics of Neurovascular Coupling in Humans. J. Physiol. 2021, 599, 3663-3676, doi:10.1113/JP281615.

23. Faraci, F.M.; Brian, J.E. Nitric oxide and the cerebral circulation. Stroke 1994, 25, 692-703, doi:10.1161/01.str.25.3.692.

24. Leffler, C.W. Nitric Oxide in Control of the Cerebral Circulation. In Nitric Oxide and the Regulation of the Peripheral Circulation; Kadowitz, P.J., McNamara, D.B., Eds.; Birkhäuser Boston: New York, 2000; pp. 113-127 ISBN 978-1-4612-1326-0.

25. Shalit, M.N.; Shimojyo, S.; Reinmuth, O.M.; Shalit, M.N. Carbon dioxide and cerebral circulatory control. I. The extravascular effect. Arch. Neurol. 1967, 17, 298-303, doi:10.1001/archneur.1967.00470270076009.

26. Skinhoj, E.; Paulson, O.B. Carbon Dioxide and Cerebral Circulatory Control: Evidence of a Nonfocal Site of Action of Carbon Dioxide on Cerebral Circulation. Arch. Neurol. 1969, 20, 249-252, doi:10.1001/archneur.1969.00480090037004.

27. Seylaz, J. Contribution to the study of the mechanism of cerebral blood flow regulation. Helv. Physiol. Pharmacol. Acta 1968, 26, 33-61.

28. Seylaz, J.; Pinard, E.; Dittmar, A.; Birer, A. Measurement of Blood Flow, Tissue PO2 and Tissue PCO2 Continuously and Simultaneously in the Same Structure of the Brain. Med. Biol. Eng. Comput. 1979, 17, 19-24, doi:10.1007/BF02440949.

29. Scremin, O.U.; Scremin, A.M.; Somani, S.M.; Giacobini, E. Brain Regional Distribution of Physostigmine and Its Relation to Cerebral Blood Flow following Intravenous Administration in Rats. J. Neurosci. Res. 1990, 26, 188-195, doi:10.1002/jnr.490260208.

30. Rovere, A.A.; Scremin, O.U.; Beresi, M.R.; Raynald, A.C.; Giardini, A. Cholinergic Mechanism in the Cerebrovascular Action of Carbon Dioxide. Stroke 1973, 4, 969-72, doi:10.1161/01.str.4.6.969.

31. Kawamura, Y.; Meyer, J.S.; Hiromoto, H.; Aoyagi, M.; Tagashira, Y.; Ott, E.O. Neurogenic Control of Cerebral Blood Flow in the Baboon. J. Neurosurg. 1975, 43, 676-88, doi:10.3171/jns.1975.43.6.0676.

32. Busija, D.W.; Heistad, D.D. Effects of Cholinergic Nerves on Cerebral Blood Flow in Cats. Circ. Res. 
1981, 48, 62-69, doi:10.1161/01.res.48.1.62.

33. Scremin, O.U.; Sonnenschein, R.R.; Rubinstein, E.H. Cholinergic Cerebral Vasodilatation in the Rabbit: Absence of Concomitant Metabolic Activation. J. Cereb. Blood Flow Metab. 1982, 2, 241-247, doi:10.1038/jcbfm.1982.24.

34. Shohami, E.; Sidi, A. Accumulation of Prostacyclin in Rat Brain During Haemorrhagic HypotensionPossible Role of PGI2 in Autoregulation. J. Cereb. Blood Flow Metab. 1984, 4, 107-9, doi:10.1038/jcbfm.1984.14.

35. Pickard, J.D. Role of Prostaglandins and Arachidonic Acid Derivatives in the Coupling of Cerebral Blood Flow to Cerebral Metabolism. J. Cereb. Blood Flow Metab. 2016, 1, 361-84, doi:10.1038/jcbfm.1981.41.

36. Iadecola, C. Does Nitric Oxide Mediate the Increases in Cerebral Blood Flow Elicited by Hypercapnia? Proc. Natl. Acad. Sci. U. S. A. 1992, 89, 3913-3916, doi:10.1073/pnas.89.9.3913.

37. Panerai, R.B.; Evans, D.H.; Naylor, A.R. Influence of arterial blood pressure on cerebrovascular reactivity. Stroke 1999, 30, 1293-5.

38. Hoiland, R.L.; Caldwell, H.G.; Carr, J.M.J.. R.; Howe, C.A.; Stacey, B.S.; Dawkins, T.; Wakeham, D.J.; Tremblay, J.C.; Tymko, M.M.; Patrician, A.; et al. Nitric oxide contributes to cerebrovascular shear-mediated dilatation but not steady-state cerebrovascular reactivity to carbon dioxide. J. Physiol. 2021, doi:10.1113/JP282427.

39. Lucas, S.J.E.; Tzeng, Y.C.; Galvin, S.D.; Thomas, K.N.; Ogoh, S.; Ainslie, P.N. Influence of changes in blood pressure on cerebral perfusion and oxygenation. Hypertension 2010, 55, 698-705, doi:10.1161/HYPERTENSIONAHA.109.146290.

40. Smirl, J.D.; Hoffman, K.; Tzeng, Y.C.; Hansen, A.; Ainslie, A.P.N. Methodological comparison of active- and passive-driven oscillations in blood pressure; implications for the assessment of cerebral pressure-flow relationships. J. Appl. Physiol. 2015, 119, 487-501, doi:10.1152/japplphysiol.00264.2015.

41. Nippert, A.R.; Biesecker, K.R.; Newman, E.A. Mechanisms Mediating Functional Hyperemia in the Brain. Neuroscientist 2018, 24, 73-83, doi:10.1177/1073858417703033.

42. Poplawsky, A.J.; Iordanova, B.; Vazquez, A.L.; Kim, S.-G.; Fukuda, M. Postsynaptic Activity of Inhibitory Neurons evokes Hemodynamic fMRI Responses. Neuroimage 2021, 225, 117457, doi:10.1016/j.neuroimage.2020.117457.

43. Tellegen, A.; Atkinson, G. Openness to Absorbing and Self-Altering Experiences (“Absorption”), A Trait related to Hypnotic Susceptibility. J. Abnorm. Psychol. 1974, 83, 268-77, doi:10.1037/h0036681.

44. Presciuttini, S.; Gialluisi, A.; Barbuti, S.; Curcio, M.; Scatena, F.; Carli, G.; Santarcangelo, E.L. Hypnotizability and Catechol-O-Methyltransferase (COMT) polymorphysms in Italians. Front. Hum. Neurosci. 2014, 7, 1-6, doi:10.3389/fnhum.2013.00929.

45. Rominger, C.; Weiss, E.M.; Nagl, S.; Niederstätter, H.; Parson, W.; Papousek, I. Carriers of the COMT Met/Met allele have higher degrees of hypnotizability, provided that they have good attentional control: a case of gene-trait interaction. Int. J. Clin. Exp. Hypn. 2014, 62, 455-82, doi:10.1080/00207144.2014.931177.

46. Guillot, A.; Collet, C.; Nguyen, V.A.; Malouin, F.; Richards, C.; Doyon, J. Functional Neuroanatomical Networks Associated with Expertise in Motor Imagery. Neuroimage 2008, 41, 1471-83, doi:10.1016/j.neuroimage.2008.03.042.

47. Cavallaro, F.I.; Cacace, I.; Testa, M. Del; Andre, P.; Carli, G.; Pascalis, V. De; Rocchi, R.; 
Santarcangelo, E.L. Hypnotizability-related EEG Alpha and Theta Activities during Visual and Somesthetic Imageries. Neurosci. Lett. 2010, 470, 13-8, doi:10.1016/j.neulet.2009.12.044.

48. Ibáñez-Marcelo, E.; Campioni, L.; Manzoni, D.; Santarcangelo, E.L.; Petri, G. Spectral and Topological Analyses of the Cortical Representation of the Head Position: Does Hypnotizability Matter? Brain Behav. 2019, 9, e01277, doi:10.1002/brb3.1277.

49. Oldfield, R.C. The Assessment and Analysis of Handedness: The Edinburgh Inventory. Neuropsychologia 1971, 9, 97-113, doi:10.1016/0028-3932(71)90067-4.

50. Weitzenhoffer, A.M.; Hilgard, E.R. Stanford Hypnotic Susceptibility Scale, Forms A and B. Consult. Psychol. Press 1959.

51. Ferrari, M.; Muthalib, M.; Quaresima, V. The Use of Near-Infrared Spectroscopy in Understanding Skeletal Muscle Physiology: Recent Developments. Philos. Trans. R. Soc. A Math. Phys. Eng. Sci. 2011, 369, 4577-90.

52. Matcher, S.J.; Elwell, C.E.; Cooper, C.E.; Cope, M.; Delpy, D.T. Performance Comparison of Several Published Tissue Near-Infrared Spectroscopy Algorithms. Anal. Biochem. 1995, 227, 54-68, doi:10.1006/abio.1995.1252.

53. Spires, J.; Lai, N.; Zhou, H.; Saidel, G.M. Hemoglobin and Myoglobin Contributions to Skeletal Muscle Oxygenation in Response to Exercise; Adv Exp Med Biol, 2011; Vol. 701;.

54. Messere, A.; Tschakovsky, M.; Seddone, S.; Lulli, G.; Franco, W.; Maffiodo, D.; Ferraresi, C.; Roatta, S. Hyper-Oxygenation Attenuates the Rapid Vasodilatory Response to Muscle Contraction and Compression. Front. Physiol. 2018, 9, 1078, doi:10.3389/fphys.2018.01078.

55. Csipo, T.; Lipecz, A.; Mukli, P.; Bahadli, D.; Abdulhussein, O.; Owens, C.D.; Tarantini, S.; Hand, R.A.; Yabluchanska, V.; Mikhail Kellawan, J.; et al. Increased cognitive workload evokes greater neurovascular coupling responses in healthy young adults. PLoS One 2021, 16, 1-16, doi:10.1371/journal.pone.0250043.

56. Pascalis, V. De; Bellusci, A.; Russo, P.M. Italian Norms for the Stanford Hypnotic Susceptibility Scale, Form C. Int. J. Clin. Exp. Hypn. 2000, 48, 315-23, doi:10.1080/00207140008415249.

57. Sitaram, R.; Caria, A.; Birbaumer, N. Hemodynamic brain-computer interfaces for communication and rehabilitation. Neural Networks 2009, 22, 1320-8, doi:10.1016/j.neunet.2009.05.009.

58. Pfurtscheller, G.; Bauernfeind, G.; Wriessnegger, S.C.; Neuper, C. Focal frontal (de)oxyhemoglobin responses during simple arithmetic. Int. J. Psychophysiol. 2010, 76, 186-92, doi:10.1016/j.ijpsycho.2010.03.013.

59. Verner, M.; Herrmann, M.J.; Troche, S.J.; Roebers, C.M.; Rammsayer, T.H. Cortical oxygen consumption in mental arithmetic as a function of task difficulty: a near-infrared spectroscopy approach. Front. Hum. Neurosci. 2013, 7, 1-9, doi:10.3389/fnhum.2013.00217.

60. Al-Rawi, P.G.; Kirkpatrick, P.J. Tissue oxygen index: thresholds for cerebral ischemia using nearinfrared spectroscopy. Stroke 2006, 37, 2720-5, doi:10.1161/01.STR.0000244807.99073.ae.

61. Canova, D.; Roatta, S.; Bosone, D.; Micieli, G. Inconsistent detection of changes in cerebral blood volume by near infrared spectroscopy in standard clinical tests. J. Appl. Physiol. 2011, 110, 1646-1655, doi:10.1152/japplphysiol.00003.2011.

62. Moerman, A.T.; Vandenheuvel, M.; Tuybens, P.J.; Van Gompel, C.; De Hert, S.G. Incongruous effect of phenylephrine on changes in cerebral blood volume measured by near-infrared spectroscopy (NIRS) indicating extracranial contamination. J. Clin. Monit. Comput. 2021, doi:10.1007/s10877-021-007023. 
63. Yang, H.C.; Liang, Z.; Vike, N.L.; Lee, T.; Rispoli, J. V.; Nauman, E.A.; Talavage, T.M.; Tong, Y. Characterizing near-infrared spectroscopy signal under hypercapnia. J. Biophotonics 2020, 13, doi:10.1002/jbio.202000173.

64. Canova, D.; Roatta, S.; Micieli, G.; Bosone, D. Cerebral oxygenation and haemodynamic effects induced by nimodipine in healthy subjects. Funct. Neurol. 2012, 27, 169.

65. Alderliesten, T.; De Vis, J.B.; Lemmers, P.M.A.; van Bel, F.; Benders, M.J.N.L.; Hendrikse, J.; Petersen, E.T. Simultaneous quantitative assessment of cerebral physiology using respiratory-calibrated MRI and near-infrared spectroscopy in healthy adults. Neuroimage 2014, 85 Pt 1, 255-263, doi:10.1016/j.neuroimage.2013.07.015.

66. Rastogi, R.; Morgan, B.J.; Badr, M.S.; Chowdhuri, S. Hypercapnia-induced vasodilation in the cerebral circulation is reduced in older adults with sleep-disordered breathing. J. Appl. Physiol. 2022, 132, 1423, doi:10.1152/japplphysiol.00347.2021.

67. Zambach, S.A.; Cai, C.; Helms, H.C.C.; Hald, B.O.; Dong, Y.; Fordsmann, J.C.; Nielsen, R.M.; Hu, J.; Lønstrup, M.; Brodin, B.; et al. Precapillary sphincters and pericytes at first-order capillaries as key regulators for brain capillary perfusion. Proc. Natl. Acad. Sci. U. S. A. 2021, 118, 1-10, doi:10.1073/pnas.2023749118.

68. Porta, A.; Gelpi, F.; Bari, V.; Cairo, B.; De Maria, B.; Panzetti, C.M.; Cornara, N.; Bertoldo, E.G.; Fiolo, V.; Callus, E.; et al. Monitoring the Evolution of Asynchrony between Mean Arterial Pressure and Mean Cerebral Blood Flow via Cross-Entropy Methods. Entropy 2022, 24, 80, doi:10.3390/e24010080.

69. Younger, J.W.; Rossetti, G.C.; Borckardt, J.J.; Smith, A.R.; Tasso, A.F.; Nash, M.R. Hypnotizability and somatic complaints: a gender-specific phenomenon. Int. J. Clin. Exp. Hypn. 2007, 55, 1-13, doi:10.1080/00207140600995745.

70. Facco, E.; Testoni, I.; Ronconi, L.; Casiglia, E.; Zanette, G.; Spiegel, D. Psychological Features of Hypnotizability: A First Step Towards Its Empirical Definition. Int. J. Clin. Exp. Hypn. 2017, 65, 98119, doi:10.1080/00207144.2017.1246881.

71. Gordon, G.R.J.; Howarth, C.; MacVicar, B.A. Bidirectional Control of Blood Flow by Astrocytes: A Role for Tissue Oxygen and Other Metabolic Factors. Adv. Exp. Med. Biol. 2016, 903, 209-19, doi:10.1007/978-1-4899-7678-9_15.

72. Acunzo, D.J.; Oakley, D.A.; Terhune, D.B. The neurochemistry of hypnotic suggestion. Am. J. Clin. Hypn. 2021, 63, 355-371, doi:10.1080/00029157.2020.1865869.

73. Santarcangelo, E.L.; Scattina, E. Responding to Sensorimotor Suggestions: From Endothelial Nitric Oxide to the Functional Equivalence Between Imagery and Perception. Int. J. Clin. Exp. Hypn. 2019, 67, 394-407, doi:10.1080/00207144.2019.1649539. 